\title{
The Small Heat Shock Protein $\alpha$-Crystallin B Shows Neuroprotective Properties in a Glaucoma Animal Model
}

\author{
Fabian Anders ${ }^{1}$, Aiwei Liu ${ }^{1}$, Carolina Mann ${ }^{1}$, Julia Teister ${ }^{1}$, Jasmin Lauzi ${ }^{1}$, Solon Thanos ${ }^{2}$, \\ Franz H. Grus ${ }^{1}$, Norbert Pfeiffer ${ }^{1}$ and Verena Prokosch ${ }^{1, *}$ \\ 1 Experimental Ophthalmology, Department of Ophthalmology, University Medical Center of the Johannes \\ Gutenberg-University Mainz, Langenbeckstrasse 1, 55131 Mainz, Germany; fanders@eye-research.org (F.A.); \\ aliu@eye-research.org (A.L.); cmann@students.uni-mainz.de (C.M.); jteister@eye-research.org (J.T.); \\ jasminschweikhard@gmx.de (J.L.); grus@eye-research.org (F.H.G.); \\ norbert.pfeiffer@unimedizin-mainz.de (N.P.) \\ 2 Department of Experimental Ophthalmology, School of Medicine, University of Münster, \\ Albert-Schweitzer-Campus 1, 48149 Münster, Germany; solon@uni-muenster.de \\ * Correspondence: vprokosch@gmx.de; Tel.: +49-6131-17-6038
}

Received: 22 October 2017; Accepted: 12 November 2017; Published: 14 November 2017

\begin{abstract}
Glaucoma is a neurodegenerative disease that leads to irreversible retinal ganglion cell (RGC) loss and is one of the main causes of blindness worldwide. The pathogenesis of glaucoma remains unclear, and novel approaches for neuroprotective treatments are urgently needed. Previous studies have revealed significant down-regulation of $\alpha$-crystallin B as an initial reaction to elevated intraocular pressure (IOP), followed by a clear but delayed up-regulation, suggesting that this small heat-shock protein plays a pathophysiological role in the disease. This study analyzed the neuroprotective effect of $\alpha$-crystallin B in an experimental animal model of glaucoma. Significant IOP elevation induced by episcleral vein cauterization resulted in a considerable impairment of the RGCs and the retinal nerve fiber layer. An intravitreal injection of $\alpha$-crystallin B at the time of the IOP increase was able to rescue the RGCs, as measured in a functional photopic electroretinogram, retinal nerve fiber layer thickness, and RGC counts. Mass-spectrometry-based proteomics and antibody-microarray measurements indicated that a $\alpha$-crystallin injection distinctly up-regulated all of the subclasses $(\alpha$, $\beta$, and $\gamma$ ) of the crystallin protein family. The creation of an interactive protein network revealed clear correlations between individual proteins, which showed a regulatory shift resulting from the crystallin injection. The neuroprotective properties of $\alpha$-crystallin B further demonstrate the potential importance of crystallin proteins in developing therapeutic options for glaucoma.
\end{abstract}

Keywords: experimental glaucoma; $\alpha$-crystallin B; neuroprotection; proteomics

\section{Introduction}

Glaucoma is a neurodegenerative disorder affecting the optic nerve head that causes the irreversible loss of retinal ganglion cells (RGCs) [1,2]. Glaucoma is one of the leading causes of blindness worldwide [3], and its prevalence is predicted to increase dramatically in the foreseeable future [4]. The mainstay of treatment is based on lowering the intraocular pressure, which is the main risk factor. However, glaucoma may also occur and progress in patients with a normal intraocular pressure (IOP), or successful IOP reduction [5-7]. The pathophysiology of glaucoma remains unclear.

Factors additional to the IOP increase, such as lamina cribrosa alterations, ocular tissue stiffness, diminished resilience of RGCs [8,9] vascular defects, reactive oxygen species, high glutamate levels, and overproduction of nitric oxide causing apoptosis, have also been suspected to play important roles 
in glaucoma [10-14]. However, the definitive pathophysiological mechanisms underlying the course of this disease remain elusive.

In vivo experimental models of glaucoma remain one of the most promising approaches to obtaining further insights into the origin of glaucoma and its pathogenesis and the associated molecular alterations within the retina. A particularly interesting protein family in this context is the crystallins, which are major structural proteins of the lens that have been widely reported as being essential in retinal and also CNS structures. The protein family itself is rather heterogeneous, and comprises three different subgroups: $\alpha, \beta$, and $\gamma$. Recent studies found shifts in $\alpha$ - and $\beta$-crystallin regulation in glaucoma animal trials during different stages of RGC loss $[15,16]$.

$\alpha$-Crystallins have already been described in various other neurodegenerative diseases, such as Alzheimer's disease and Parkinson's disease [17,18], and also in the context of ocular disorders such as diabetic retinopathy and age-related macular degeneration (AMD) [19,20]. Due to their high homology with the small heat shock proteins (sHSP), $\alpha$-crystallins are believed to act as molecular chaperons in the presence of an external stimulus [21].

Thus, the aim of this study was the measure of $\alpha$-crystallin B and its potential neuroprotective properties in an experimental animal model of glaucoma with a subsequent analysis of possible alterations in downstream markers in a complex mass-spectrometric (MS) approach.

\section{Results}

\subsection{IOP Elevation}

Cauterization of the episcleral veins resulted in a significant elevation of IOP in all of the eyes where the cauterization surgery was performed. The IOP rose from a baseline level of $10.88 \pm 0.38 \mathrm{mmHg}$, to an average level of $17.94 \pm 1.72 \mathrm{mmHg}$ in the $\alpha$-crystallin $\mathrm{B}$ injected eyes and an average level of $18.48 \pm 1.63 \mathrm{mmHg}$ in the phosphate-buffered saline PBS injected eyes (Figure 1). Neither did the intravitreal injection have an influence on the IOP nor was the IOP of the contralateral eyes influenced by the surgery performed on the left eye of the animals (average IOP contralateral eye: $10.79 \pm 0.56 \mathrm{mmHg}$ ).

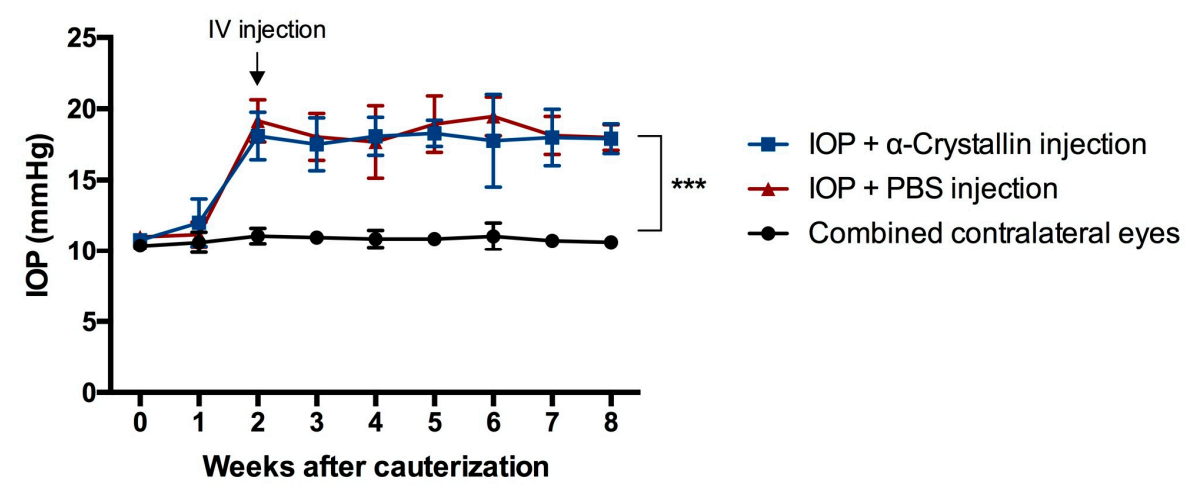

Figure 1. IOP elevation as a result of the episcleral vein cauterization. The intraocular pressure (IOP) of all cauterized eyes rose significantly $\left({ }^{* * *} p<0.001, n=11\right.$, mean $\pm \mathrm{SD}$, parametric $t$-test) two weeks after the surgical intervention. With rise of the IOP, the intravitreal (IV) injection of $\alpha$-crystallin B and PBS was performed. No noticeable influence on the IOP was observed due to the injection. The untreated contralateral eyes remained unaffected in terms of IOP changes.

\subsection{Morphological Changes}

Elevation of the IOP resulted in considerable changes in the RGC density and RNFL thickness (Figure 2). When compared to the RGC density of the contralateral eyes with $1771 \pm 238.9 \mathrm{RGC} / \mathrm{mm}^{2}$, the $\alpha$-crystallin B injected eyes lost $12 \%$ RGCs $\left(1560 \pm 153.6 \mathrm{RGC} / \mathrm{mm}^{2}\right.$, not significant) and the PBS injected eyes $25 \%$ RGCs $\left(1323 \pm 161.1 \mathrm{RGC} / \mathrm{mm}^{2}, p<0.01\right)$. 


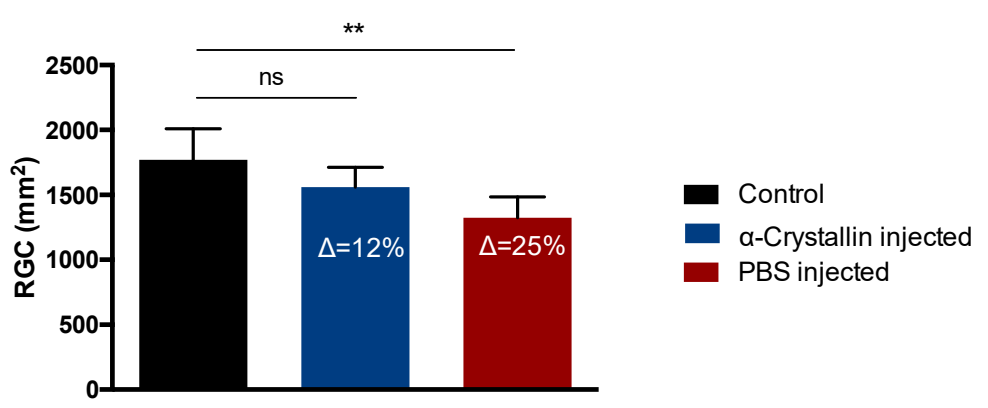

Figure 2. Quantification of RGC density in retinal flat-mounts. Elevation of the IOP resulted in an average loss of $\Delta=12 \%$ retinal ganglion cell (RGCs) in the $\alpha$-crystallin B injected animals compared to the untreated contralateral eyes, while the RGC loss in the PBS-injected animals was about $25 \%$ (** $p<0.01$, ns-not significant, $n=11$, mean \pm SD, one-way ANOVA).

With respect to the RNFLT, there was a $6 \%$ decrease between the baseline measurement and the final measurement of the contralateral control eyes $(53.18 \pm 5.9 \mu \mathrm{m}, 50.00 \pm 5.7 \mu \mathrm{m}$, not significant), an $8 \%$ decrease within the crystallin-injected group $(51.40 \pm 4.8 \mu \mathrm{m}, 47.60 \pm 3.6 \mu \mathrm{m}$, not significant), and a $22 \%$ reduction of the RNFLT in the PBS-injected group $(52.00 \pm 2.6 \mu \mathrm{m}, 40.75 \pm 5.4 \mu \mathrm{m}, p<0.01)$ (Figure 3).

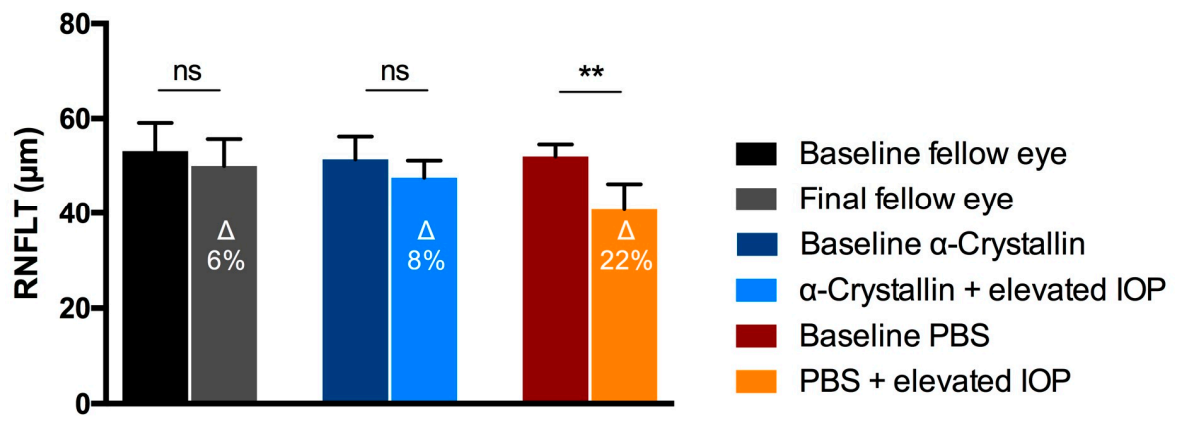

Figure 3. Survey of the retinal nerve fiber layer thickness using optical coherence tomography. Untreated contralateral eyes showed a $6 \%$ decrease of the retinal nerve fiber layer thickness (RNFLT) during the time of the study. IOP elevation and $\alpha$-crystallin B injection effectuated in a loss of $\Delta=8 \%$, while PBS-injected eyes showed a decrease of $\Delta=22 \%$ with respect to retinal nerve fiber layer (RNFL) thickness ${ }^{* *} p<0.01$, ns-not significant, $n=5$, mean \pm SD, one-way ANOVA).

\subsection{Functional Changes}

The Ganzfeld Photopic Electroretinogram (ERG) showed considerable changes in the B-wave and the photopic negative response (PhNR) between the ERG patterns of the contralateral eyes when compared to the eyes with elevated IOP (Figure 4). Nevertheless, differences of the B-wave and PhNR amplitudes were more distinct in the PBS-injected animals as compared to the respective contralateral eyes (B-wave: $\Delta=37 \%$, PhNR: $\Delta=24 \%$ ) than was the case in the crystallin-injected group (B-wave: $\Delta=26 \%$, PhNR: $\Delta=7 \%$ ). 

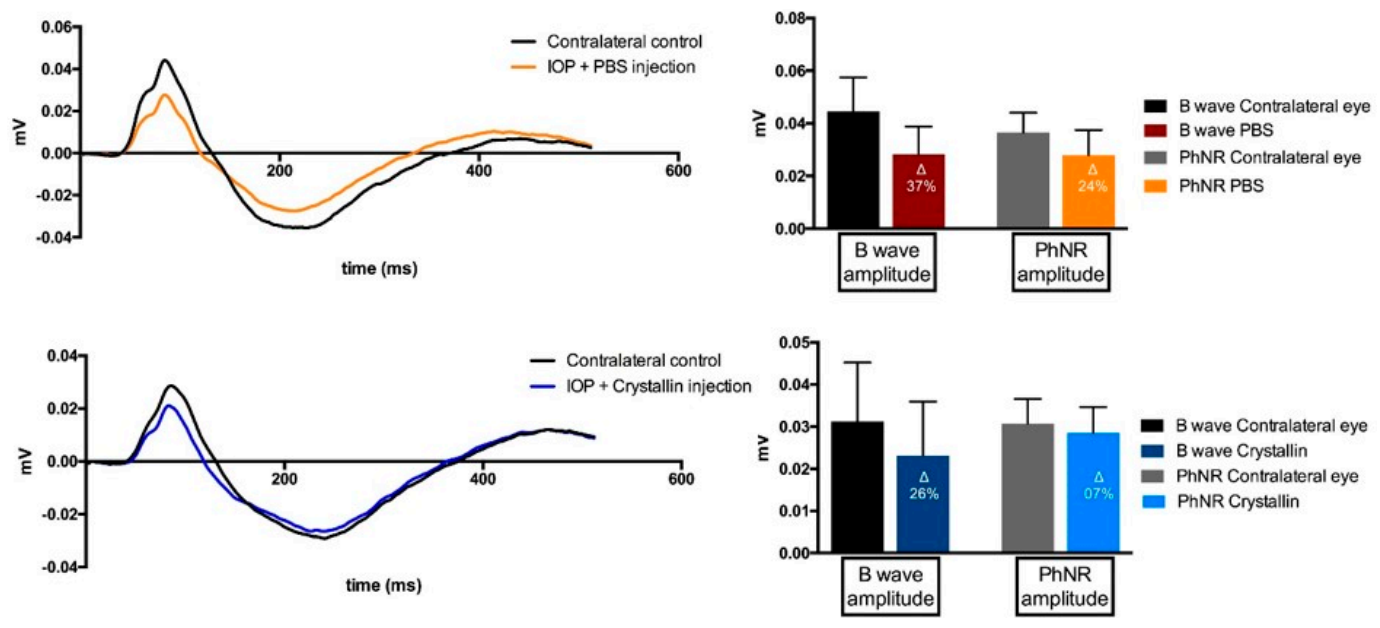

Figure 4. Pattern of the ganzfeld photopic electroretinogram analysis. ERG results showed considerable aberrances in the B-wave and photopic negative response (PhNR) between contralateral control eyes and experimental glaucoma eyes. However, the deviance to the respective control eyes seems much higher in PBS-injected eyes than in $\alpha$-crystallin B injected eyes $(n=11$, mean \pm SD). The millivolt decrease is defined in percentaged change ( $\Delta=\%$ change).

\subsection{Proteomic Analysis}

A total number of 1765 retinal proteins could be identified and quantified, whereas only a small proportion of $5 \%$ ( 87 proteins) showed an up- or down-regulation of 1.5 -fold or more when compared to the respective control group. However, mass-spectrometric measurements identified higher levels of crystallin proteins of all the subtypes $\alpha, \beta$, and $\gamma$ in the $\alpha$-crystallin B injected samples as compared to the PBS-injected controls (Figure 5).

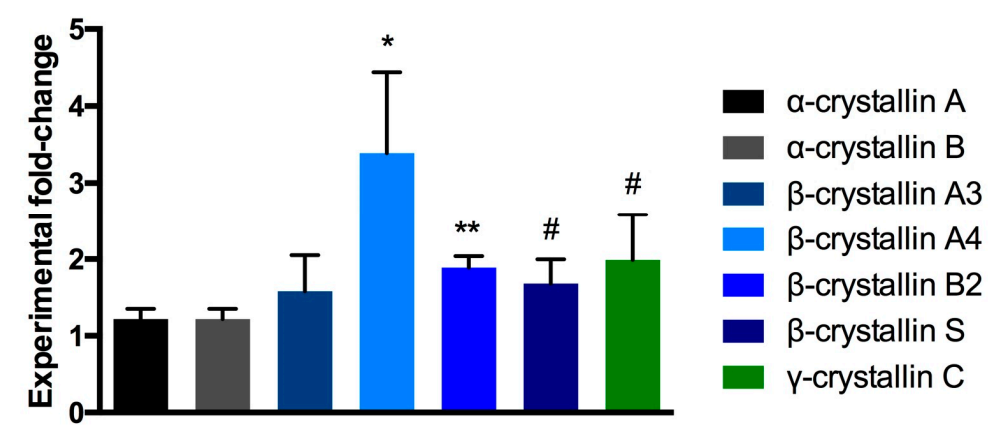

Figure 5. MS fold-change analysis of crystallin protein family members. Injection of $\alpha$-crystallin B induced moderate to distinct up-regulation of $\alpha-, \beta$-, and $\gamma$-crystallins in the retina when compared to PBS-injected retinal protein levels $\left({ }^{* *} p<0.01,{ }^{*} p<0.05\right.$, ${ }^{*} p<0.1$, unpaired parametric $t$-test, $n=4$ per exp. group, mean \pm SEM).

Creation of an interactive protein network revealed various relations between retinal proteins, identified as up-regulated (red) and down-regulated (green) through all of the cellular layers (Figure 6). Mitogen-activated protein kinase 1 and protein kinase C (yellow), which were also found in the MS data, but without a noticeable change with respect to the relative level, interact with a multitude of the displayed proteins. Caspases could not be identified within the MS measurements, but were added to the network by the IPA ${ }^{\circledR}$ software, since they interact with numerous regulated nucleus proteins. 


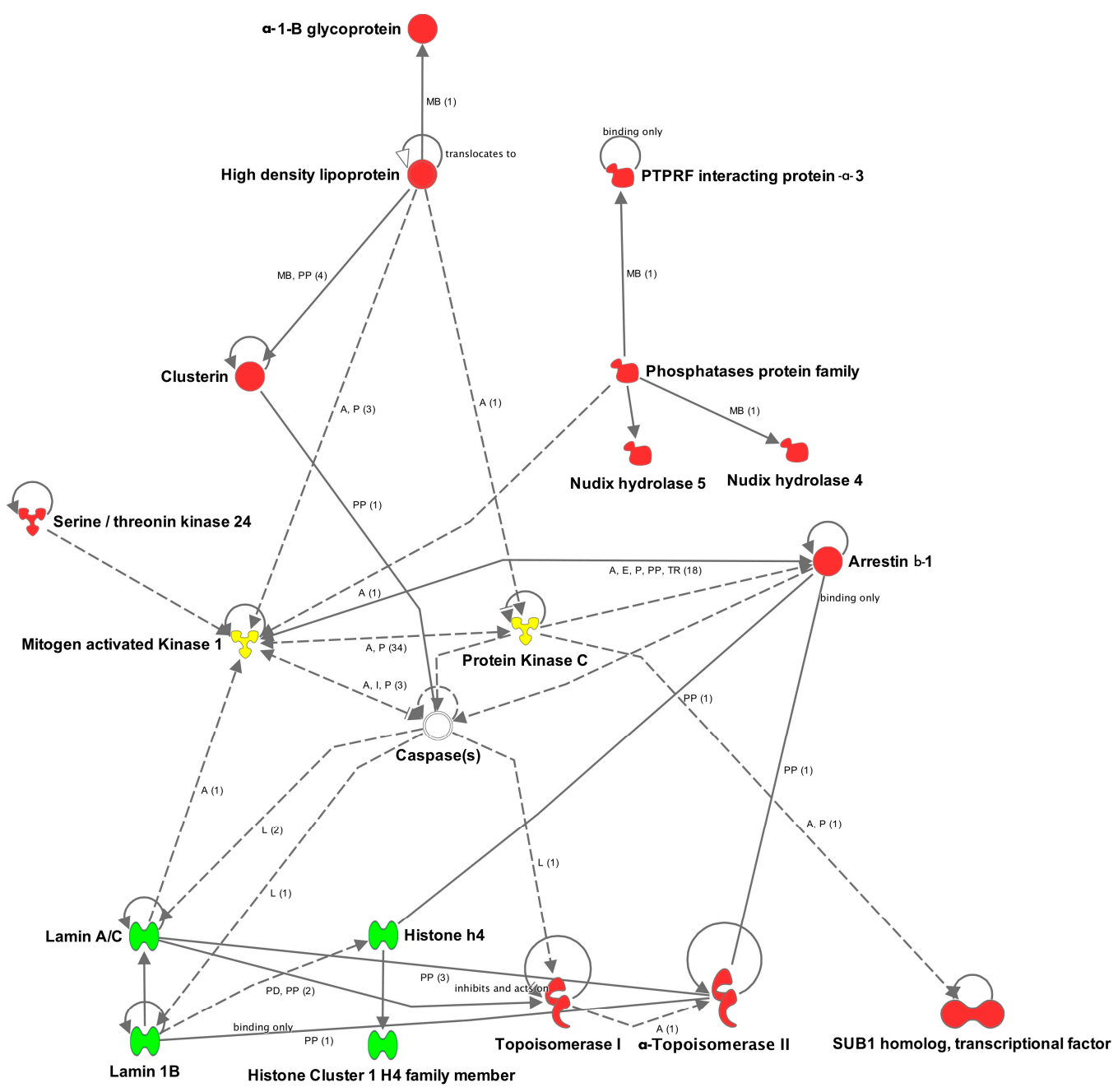

Figure 6. Ingenuity Pathway Analysis interactive protein network of highly up- or down-regulated retinal proteins. Up-regulated proteins (red) are located in the extracellular space, plasma membrane, cytoplasm, as well as in the nucleus. Down-regulated proteins in this network are exclusively located in the nucleus (green). The mitogen-activated protein kinase 1, protein kinase C (yellow) and caspase proteins show considerable interaction with a variety of displayed proteins with altered regulation levels. Legend: $\mathrm{A}=$ activation; $\mathrm{L}=$ proteolysis; $\mathrm{P}=$ phosphorylation/dephosphorylation; $\mathrm{PP}=$ protein-protein binding; $\mathrm{I}=$ inhibition; $\mathrm{E}=$ expression; $\mathrm{PD}=$ protein-DNA binding; $\mathrm{TR}=$ translocation; $\mathrm{MB}=$ group $/$ complex membership; solid arrow $=$ direct interaction; dashed arrow $=$ indirect interaction; (count) = number of scientific references on the respective relation; if not indicated differently in the figure, the arrow head indicates "acts on".

The down-regulation of the nucleus protein lamin A/C as a reaction to the $\alpha$-crystallin B injection was further validated by antibody microarray detection and could confirm the previous obtained MS-based results (Figure 7). Measured intensities indicated a two-fold increase of lamin A/C in the retinal protein-mix of PBS-injected eyes when compared to the $\alpha$-crystallin B injected group $(p<0.001)$. 


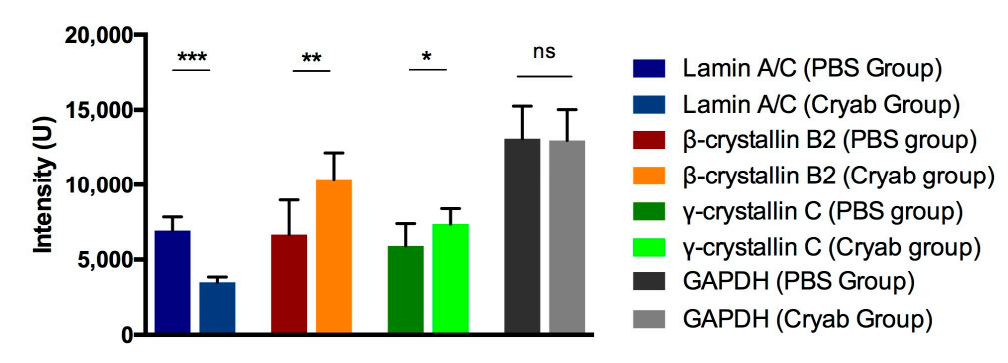

Figure 7. Antibody microarray detection of specifically altered retinal proteins. The protein regulations, detected in the MS measurements, could be validated with antibody microarray for lamin A/C, $\beta$-crystallin B2 and $\gamma$-crystallin $C$, using GAPDH for loading control purposes. Lamin A/C levels in the PBS group were significantly higher than in the crystallin-injected (cryab) group, while the levels of $\beta$-crystallin B2 and $\gamma$-crystallin $C$ were found higher in the cryab group $\left({ }^{*} p<0.05,{ }^{* *} p<0.01,{ }^{* * *} p<0.001\right.$, ns-not significant, $n=9$ per exp. group, mean $\pm \mathrm{SD}$, one-way ANOVA).

\section{Discussion}

The data obtained in this study provide further evidence for the neuroprotective effects of crystallin proteins and a potential basis for the development of novel translational glaucoma therapies. The glaucoma model that was constructed in Sprague-Dawley rats led to significant neurodegenerative effects, such as the loss of RGCs, a thinning of the retinal nerve fiber layer (RNFL), and functional alterations within the ERG pattern. However, the injection of $\alpha$-crystallin B prior to the IOP elevation was able to markedly mitigate these neurodegenerative processes.

The neuronal damage that was induced by occluding episcleral veins and the subsequent elevation of the IOP were highly consistent with the results obtained in previous comparable glaucoma studies $[15,20,22]$. Regarding the ERG, a low signal for the PhNR amplitude was expected, given the significant loss of RGCs [23], but the changed B-wave amplitude indicated that other retinal segments had also been damaged. However, comparable results have already found in glaucoma models in rats and mice [24,25]. As Nork et al. reported in 2000, chronically elevated IOP can also affect photoreceptor cells, which could explain the observed B-wave changes [26]. Also, Hernandez et al. described molecular changes in the inner retina during different periods of elevated IOP, which is a clear sign that structures additional to RGCs are functionally altered in experimental glaucoma models [27].

At both the morphological and functional levels, the injection of $\alpha$-crystallin B induced distinct neuroprotective effects in glaucomatous eyes when compared to the glaucomatous eyes that were injected with PBS as controls. No significant difference in RGC density was observable between untreated and crystallin-injected eyes. Also, the decrease in RNFL was almost identical to that in the contralateral eyes. The PhNR amplitudes in the ERG pattern only differed slightly between the crystallin-injected and the untreated contralateral eyes.

Protective effects of $\alpha$-crystallins have already been reported for acute inflammation, diabetic retinopathy, multiple sclerosis, and UVA-induced photoreceptor apoptosis [28-31]. Doss et al. questioned the role of $\alpha$-crystallins in primary open-angle glaucoma already back in 1998 [32]. Several studies have demonstrated neuroprotective properties of crystallins in RGC survival, and even neuroregenerative effects have been attributed to this particular protein group based on findings in experimental glaucoma models [33-36]. However, the precise mode of action of these protective effects remains unclear. Fischer et al. reported crystallin-mediated astrocyte-derived CNTF as the main reason for the protective effects of crystallins in the retina, while other authors have described the indirect inhibition of c-Jun N-terminal kinases and double-stranded RNA-dependent protein kinases $[33,37,38]$. To the best of our knowledge, the present study is the first to provide indications that the injection of a certain member of the crystallin family can stimulate the expression of numerous crystallin proteins covering all of the subclasses. The levels of $\alpha-, \beta-$, and $\gamma$-crystallins were higher in the retina of eyes injected with $\alpha$-crystallin B than in the corresponding PBS-injected 
controls; however, it should be noted that the intravitreal injections were applied almost two months prior to the animals being sacrificed. Anyhow, it is noticeable that specifically the relative protein level of $\alpha$-crystallin B was only moderately higher with a fold-change of 1.2. Injected $\alpha$-crystallin is certainly expected to be metabolized over time. Further MS analyses and the bioinformatics-assisted creation of a protein network revealed distinct regulatory changes of retinal proteins in the extracellular space, plasma membrane, cytoplasm, and nucleus. Mitogen-activated protein kinase 1 and protein kinase $C$ appeared to interact strongly with the identified altered proteins, but were themselves found at levels equal to those in the controls.

Clusterin, which is an extracellular protein that is located in the cytoplasm that has been implicated in processes, such as cell-cycle control and apoptosis, was found to be up-regulated in the crystallin-injected retinal tissues. Clusterin functions as a chaperone and was described to be neuroprotective in the context of glaucoma in the interplay between interleukin-6 (IL-6), vascular endothelial growth factor (VEGF), and hypoxia-1 $\alpha$ [39]. Caspases, which have a direct binding relation to clusterin, are known to cleave lamin proteins and topoisomerase I in the nucleus $[40,41]$. Those proteins directly influence cell viability via their effects on cellular functioning and cell-death signaling. Lamin $\mathrm{A} / \mathrm{C}$ and lamin $\mathrm{B}$ were found distinctly down-regulated with fold-change ratios of 0.29 and 0.28 due to the crystallin-injection. Decreased levels of lamin A/C were further confirmed in microarray analyses. Lamin A/C was previously identified as an early marker in experimental glaucoma [42], being found to be markedly up-regulated in response to short-term IOP elevation or initial neuronal impairment. The injection of $\alpha$-crystallin B may counterbalance the increase of lamins in this connection. Lamin proteins are known to have a direct association to cellular apoptosis [43], acting on previous cleavage by caspases $[44,45]$. The down-regulation of lamins may represent a direct link to the neuroprotective effects on RGCs, and their axons induced by the intravitreal injection of $\alpha$-crystallin B. This hypothesis is further supported by Adhikari et al. showing the colocalization of $\alpha$-crystallin B and lamin A/C in the nucleus of cells under stressful conditions [46].

$\alpha-1 \mathrm{~B}$ glycoprotein, the transcriptional repressor CTCF, and the neurofilament light polypeptide, which MS revealed were also altered, but which were not included in the displayed protein network, have previously been reported to be associated with glaucoma [47-49]. The altered proteins plectin and filamin-C are both reportedly related to $\alpha$-crystallin B in the context of neurodegeneration and myofibrillar degeneration [50,51].

It seems obvious from the data obtained in this study, combined with the numerous existing positive indications regarding neurodegenerative correlations that the family of crystallin proteins could play an important role in the development of innovative neuroprotective therapies for glaucoma. Several compounds, such as L. barbarum polysaccharide and $17 \beta$-estradiol, have already been found to exert considerable neuroprotective effects via the stimulation of retinal crystallin proteins in experimental animal models of glaucoma $[33,52]$. However, the up-regulation of crystallins in the retina appears to occur naturally as a reaction to neurodegeneration or IOP elevation, but this process appears to exhibit a temporal delay $[15,16]$. The overriding question is whether early treatment or generally higher levels of crystallin proteins can be a realistic treatment modality—combined with the classical IOP lowering procedure-in patients, and what underlying translational research is required. First and foremost, continuing studies are needed to reveal the mechanisms underlying the neuroprotective effects of crystallins in the retina, and especially which particular retinal cells primarily react to increased crystallin levels. Furthermore, advanced studies of the role of crystallin proteins in glaucoma would be needed in primates whose eye physiology and anatomy are more similar to those of humans. An up-regulation of crystallins has already been shown in human retinal tissue obtained postmortem from glaucoma patients [53]. However, despite this new knowledge about the indisputable potential of crystallins, there is still a considerable journey to cover from the laboratory bench to the patient bedsides. 


\section{Materials and Methods}

\subsection{Ethical Statement and Animal Experiments}

All of the experiments were conducted in accordance with the Association of Research in Vision and Ophthalmology (ARVO) - Statement for the Use of Animals in Ophthalmic and Vision Research. Animal trials were approved by the committee for animal research (Health Investigation Office Rhineland-Palatinate, permission number: 14-1-085; approval date: 13 October 2014). In total, eleven Sprague Dawley rats, all female and of the same age, were used for this study. All animals were housed at the translational animal research center (TARC) of the University Medical Center of the Johannes-Gutenberg University Mainz with a twelve-hour day/night cycle. Food and water were provided ad libitum. Health and behavior of the animals were checked daily by schooled staff members of the TARC, and additionally by FELASA-B educated group members, as well as group's veterinary surgeons on a weekly basis. During surgical interventions, minimizing the of animals' discomfort and pain was of the highest priority. For anesthesia, a mixture of medetomidine (Dorbene vet., Pfizer, New York, NY, USA) and Ketamine (Inresa Arzneimittel, Freiburg, Germany) was injected intramuscularly into the hamstrings and oxybuprocain (Novesine, OmniVision, Puchheim, Germany) was applied topically on the eye. To reduce postoperative pain, novaminsulfon (Novalgin, Ratiopharm, Ulm, Germany) was injected subcutaneously after the surgery. Further investigations, which required a sedated status of the animals without an invasive intervention were conducted using medetomidine exclusively.

\subsection{Episcleral Vein Cauterization}

Experimental glaucoma was induced by the occlusion of three episcleral veins, which form the trunks of the vortex veins, as shown by Shareef et al. [54]. The episcleral veins were made accessible through a careful incision of the conjunctiva. Cauterization and subsequent transection of those vessels results in a considerable elevation of IOP approximately two weeks after surgery. The episcleral veins were made accessible through a careful incision of the conjunctiva. All of the animals received this surgical intervention on the left eye, while the contralateral eye served as a control throughout the study. To ensure the effect of the vein cauterization, the IOP was measured immediately before the surgery and once a week thereafter throughout the study. IOP measurement was performed using a rebound-tonolab (iCare, Vantaa, Finland), designed for rodents. Twenty individual measurements were taken per eye and subsequently averaged. Animals were only slightly fixated through handholding and fully conscious. Device calculated average values were ignored. The animals were sacrificed after seven weeks of elevated IOP.

\subsection{Intravitreal Injection of $\alpha$-Crystallin $B$}

Recombinant produced and purified $\alpha$-crystallin B (ABIN666647, antibodies-online, Aachen, Germany) was injected into the vitreous body of six cauterized eyes two weeks after the episcleral vein occlusion, immediately after the first rise of the IOP. As a control, the remaining five animals received an injection of phosphate-buffered saline (Sigma Aldrich, St. Louis, MO, USA) into the vitreous of their cauterized eyes. The injection volume for all animals was $5 \mu \mathrm{L}$. The protein concentration of the $\alpha$-crystallin B stock was $1 \mu \mathrm{g} / \mu \mathrm{L}$. To avoid a reflux of the injected fluid, the $30 \mathrm{G}$ needle was kept intravitreal for a period of $15 \mathrm{~s}$. Care was taken not damage the lens or other surrounding tissues. The amount of injected crystallin was adapted from previous studies focusing on $\beta$-crystallin proteins [15,35]. All of the injections were performed using a Hamilton Syringe (Sigma Aldrich). Contralateral eyes received no injections at all.

\subsection{Quantification of Retinal Ganglion Cell Density}

RGC loss was determined by immunohistochemical staining against the brain-specific homeobox/POU domain protein 3A (BRN3A) in retinal flat-mounts, as shown by Nadal-Nicolas et al. [55]. After sacrifice of the animals, one quarter of each retinal tissue was carefully separated with a micro-scissor 
and subsequently fixed in $4 \%$ formalin solution for $30 \mathrm{~min}$ (Carl Roth, Karsruhe, Germany). Subsequently, the retinal tissue parts were stored in 30\% sucrose solution overnight and stained as previously described [15]. All of the retinal quarters were arranged at the site of the optic nerve head and 15 pictures were taken with a magnification of 200. Great care was taken to ensure an identical proportion of centrally and peripherally located retinal images for all individual retinal pieces. RGC quantification was performed using an ImageJ (ImageJ Fiji v_1) macro, which converted all of the pictures into a 16-bit grey scale format, following a background subtraction and auto-threshold application. The nucleus-counter particle analysis provided the final number of RGCs per picture. In addition, all pictures were manually checked for precision and accurateness of the macro.

\subsection{Optical Coherence Tomography}

Measurements of the retinal nerve fiber layer thickness (RNFLT) were performed on both eyes of all the animals at the beginning of the study before the vein cauterization, and immediately before the sacrifice. The in vivo imaging of the RNFL was accessed using a SD-OCT device (Heidelberg Engineering, Heidelberg, Germany). Pupils of the anesthetized animals were dilated by topical administration of tropicamide (Mydriaticum, Pharma Stulln, Stulln, Germany). To achieve a higher quality of the fundus picture and B-scan, a contact lens (PMMA 2.70/5.20, Cantor + Nissel, Brackley, UK) was placed on the eye during the optical coherence tomography measurements. To adjust the OCT device to rodents, the corneal radius was set to a fixed value of $7.7 \mathrm{~mm}$ and the reference arm and focus were adjusted manually for each animal to ensure the highest possible quality. A $12^{\circ} \mathrm{dm}$ circular B-scan around the optic nerve head with 100 frames per picture was taken. Subsequent segmentation of the RNFL and other retinal layers had to be performed manually with the aid of the Heidelberg Eye Explorer software v. 1.9.10.1. (Heidelberg Engineering), since the algorithm provides automated segmentation only for recordings in humans.

\subsection{Ganzfeld Photopic Electroretinogram}

All of the animals were anesthetized systemically and topically before the acquisition. After sedation, pupils were fully dilated with topical administration to a diameter of approximate $4 \mathrm{~mm}$ using Mydriaticum (Pharma Stulln). Thence, the animals were positioned properly on a custom-designed platform, and were connected with four electrodes (Roland Consult, Brandenburg, Germany): two goldring-electrodes (diameter: $4 \mathrm{~mm}$ ) to both corneas as actives, one needle-electrode with dual cables for both eyes at the top of the head as reference, and one needle-electrode in the tail serving as ground, respectively. Following the placement of the electrodes, the eyes were lubricated with 2\% Methocel (OmniVision, Puchheim, Germany) during the entire procedure. The Ganzfeld photopic ERG was recorded using a RETI system (Roland Consult): the background luminance was set to $40 \mathrm{~cd} \cdot \mathrm{s} \cdot \mathrm{m}^{-2}$ of green light; intensities of the white stimuli flash set to $-0.15,0.23,0.61,0.99$, $1.37 \log _{10} \mathrm{~cd} \cdot \mathrm{s} \cdot \mathrm{m}^{-2}$, respectively. The duration of the recording after stimulus was set to $512 \mathrm{~ms}$ (thereby sampling frequency $1 \mathrm{kHz}$ ). Artefacts were automatically filtered by the RETI system. Each record consisted of an average of over 25 responses obtained at the flash frequency of $0.33 \mathrm{~Hz}$. Sufficiency of the anesthesia depth was monitored by the ERG signal baseline. After acquisition, raw data were exported from the system and plotted in GraphPad Prism v. 6 (GraphPad Software, San Diego, CA, USA). The amplitudes of the B-wave and the photopic negative response (PhNR) were further used for statistical analysis.

\subsection{Mass Spectrometry Sample Preparation}

Retinal tissue of $\alpha$-crystallin B and PBS injected eyes was carefully separated from the parts used for IHC staining and transferred into individual $2 \mathrm{~mL}$ sample tubes in liquid nitrogen. The tissues were firstly disintegrated with a precooled mortar and subsequently lysed using $0.5 \% N$-Dodecyl $\beta$-D-maltoside (Sigma Aldrich) in PBS for one hour at $4{ }^{\circ} \mathrm{C}$. Further breakdown of the retinal cells was facilitated using an ultrasonic bath for $30 \mathrm{~min}$ on ice and multiple impulses of an ultrasonic 
wand. The protein concentration for each sample was determined with a BCA Pierce Protein Assay kit (Thermo Fisher, Waltham, MA, USA), and $10 \mu \mathrm{g}$ of the total protein mixture was transferred into $1 \times$ LDS sample buffer (NuPAGE, Thermo Fisher) containing 0.1 M DTT. Each sample was subsequently boiled at $70{ }^{\circ} \mathrm{C}$ for ten minutes and separated on a 4-12\% NuPAGE Novex Bis-Tris precast gel (Life Technologies, Waltham, MA, USA) for ten minutes at $180 \mathrm{~V}$ in $1 \times$ MOPS buffer. The individual gel lanes were further cut into one piece per lane and were destained with $50 \%$ ethanol and $25 \mathrm{mM}$ ammonium bicarbonate $(\mathrm{ABC})$. After dehydration with $100 \%$ acetonitrile $(\mathrm{ACN})$, the gel pieces were digested using trypsin at $37^{\circ} \mathrm{C}$ overnight. The tryptic peptides were extracted twice with $3 \%$ TFA and $30 \%$ CAN, concentrated with an Eppendorf concentrator and passed through a $\mathrm{C}_{18}$ Stage Tip [56].

\subsection{MS Measurement and Data Analysis}

The samples were injected through the autosampler unit into an Ultra High Performance Liquid Chromatography (uHPLC) system (EASY-nLC 1000, Thermo Fisher). The peptides were subsequently loaded on a 25-cm capillary (C18-AQ $1.9 \mu \mathrm{m}$ resin, Dr. Maisch GmbH, Ammerbuch, Germany) for the reverse-phase chromatography. The HPLC system was directly mounted to a Q Exactive Plus mass spectrometer (Thermo Fisher) with a $90 \mathrm{~min}$ optimized gradient from 2 to $40 \%$ ACN with $0.1 \%$ formic acid at a flow rate of $200 \mathrm{~nL} / \mathrm{min}$. Chromatography stabilization, spray voltage range, and MS mode were the same, as previously described [57]. The MS full scans were obtained in the orbitrap with a resolution of 70,000, while the MS/MS scan resolution was set to 17,500. Obtained raw files were processed with MaxQuant (version 1.5.3.30) and search against the Swiss-Prot annotated protein database of Rattus norvegicus (10116). Carbamidomethyl (Cys) was set as fixed modification, while acetyl (N-term protein) and oxidation (Met) were considered as variable modifications. Only proteins with at least two ratio counts based on unmodified unique- or razor-peptides were quantified with an applied false-discovery rate (FDR) of $1 \%$. Identified proteins with a ratio count below two were not reported into the final files. The obtained label-free quantification (LFQ) intensities were further used for the fold-change ratio calculation. The mass spectrometry proteomics data have been deposited to the ProteomeXchange Consortium via the PRIDE [58] partner repository with the dataset identifier PXD007751. Additionally to the raw files in the repository, all proteins, including their regulation fold-change and LFQ intensity, can be found in the supplementary files.

\subsection{Antibody Microarray}

Lamin A/C $(0.1 \mathrm{mg} / \mathrm{mL}), \beta$-crystallin B2 $(0.25 \mathrm{mg} / \mathrm{mL})$, and $\gamma$-crystallin $\mathrm{C}(1 \mathrm{mg} / \mathrm{mL})$ antibodies were spotted with nine technical replicates per subarray on a glass-nitrocellulose 16 multi-pad slide (Oncyte, Grace Bio-Labs, Bend, OR, USA) using a non-contact array spotter (ciFLEXARRAYER 3, Scienion, Berlin, Germany). As a loading control, GAPDH $(1 \mathrm{mg} / \mathrm{mL})$ antibodies were spotted on the same subarrays in the same manner. The retinal protein mix was labeled with Dylight 649 NHS Ester (Cy5) (Thermo Fisher) following the manufactures protocol. After one hour of incubation with the dye, the reaction was stopped by adding $100 \mu \mathrm{L}$ of $\mathrm{HCl}$-Tris for another hour. In the meantime, the array slide was blocked with Grace Bio-Labs Super G blocking buffer (Sigma Aldrich) for one hour and subsequently washed with $0.5 \%$ Tween in PBS (three times, $10 \mathrm{~min}$ ). Afterwards the Dylight-labeled protein mixes (10 $\mu \mathrm{g}$ in total) from the particular experimental groups were loaded onto the individual subarrays and incubated for $2.5 \mathrm{~h}$. To remove unbound proteins, the slide was washed again three times with $0.5 \%$ Tween in PBS and subsequently dried in a SpeedVac-Concentrator for two minutes (Eppendorf, Hamburg, Germany). Finally, the emitted fluorescence signals were scanned with a high-resolution confocal array scanner (Affymetrix 428, Santa Clara, CA, USA) at a gain of $10 \mathrm{~dB}$ and a line average of 10. Digitized signals were analyzed with Imagene 5.5 (BioDiscovery Inc., El Segundo, CA, USA). 


\subsection{Bioinformatics Analysis and Proteomic Networks}

Considerably altered proteins (exp. Fold-change $>1.5$ ), determined by their relative regulation between the crystallin- and the PBS-injected group, were further processed to the Ingenuity Pathway Analysis IPA ${ }^{\circledR}$ software (version v.01-04, Qiagen, Venlo, The Netherlands). Protein relations and networks were calculated accordingly using Fisher's exact test with a significance level of 0.05 . Only altered proteins were provided to the IPA ${ }^{\circledR}$ software in order to generate the interaction network. However IPA ${ }^{\circledR}$ may add a minor amount of additional proteins to generate a broader spectrum of protein/protein relations.

\subsection{Experimental Design and Statistics}

All data obtained from the experimental groups of $\alpha$-crystallin B injected eyes, PBS injected eyes and untreated contralateral eyes was checked for Gaussian distribution. Parametric $t$-tests and one-way ANOVA testing was performed accordingly using Prism GraphPad v.6. A $p$-value $\leq 0.05$ was considered as statistically significant. If not indicated differently, all data is provided with mean $\pm \mathrm{SD}$.

Supplementary Materials: Supplementary materials can be found at www.mdpi.com/1422-0067/18/11/2418/s1.

Acknowledgments: Support by IMB Proteomics Core Facility is gratefully acknowledged (instrument funded by DFG INST 247/766-1 FUGG).

Author Contributions: Fabian Anders and Verena Prokosch planned the concept and experimental design of this study. Fabian Anders and Aiwei Liu performed the ERG measurements. Episcleral vein cauterization as well as enucleation was done by Carolina Mann exclusively. Fabian Anders, Julia Teister, Jasmin Lauzi and Aiwei Liu performed the OCT scans and immunostainings for the RGC quantification. Proteomic analyses were done by Fabian Anders in cooperation with the proteomic core facility of the IMB Mainz. Solon Thanos, Franz H. Grus and Norbert Pfeiffer provided scientific advice for structure of experiments and manuscript. All authors read and revised the manuscript critically.

Conflicts of Interest: The authors declare no conflict of interest.

\section{Abbreviations}

$\begin{array}{ll}\text { ACN } & \text { Acetonitrile } \\ \text { AMD } & \text { Age-related macular degeneration } \\ \text { ARVO } & \text { Association of Research in Vision and Ophthalmology } \\ \text { BRN3A } & \text { Brain-specific homeobox/POU domain protein 3A } \\ \text { CNTF } & \text { Ciliary neurotrophic factor } \\ \text { Cryab } & \text { a-crystallin B } \\ \text { ERG } & \text { Electroretinogram } \\ \text { FDR } & \text { False discovery rate } \\ \text { GAPDH } & \text { Glyceraldehyde 3-phosphate dehydrogenase } \\ \text { IL-6 } & \text { Interleukin 6 } \\ \text { IOP } & \text { Intraocular pressure } \\ \text { IV } & \text { intravitreal } \\ \text { LFQ } & \text { Label-free quantification } \\ \text { MS } & \text { Mass-spectrometry } \\ \text { PBS } & \text { phosphate-buffered saline } \\ \text { PhNR } & \text { Photopic negative response } \\ \text { RGC } & \text { Retinal ganglion cell } \\ \text { RNFL } & \text { Retinal nerve fiber layer } \\ \text { RNFLT } & \text { Retinal nerve fiber layer thickness } \\ \text { sHSP } & \text { Small heat shock protein } \\ \text { TARC } & \text { Translational animal research center } \\ \text { uHPLC } & \text { Ultra-high pressure liquid chromatography } \\ \text { UVA } & \text { Ultraviolet A radiation } \\ \text { VEGF } & \text { Vascular endothelial growth factor } \\ & \end{array}$




\section{References}

1. Weinreb, R.N.; Aung, T.; Medeiros, F.A. The pathophysiology and treatment of glaucoma: A review. JAMA 2014, 311, 1901-1911. [CrossRef] [PubMed]

2. Jonas, J.B.; Aung, T.; Bourne, R.R.; Bron, A.M.; Ritch, R.; Panda-Jonas, S. Glaucoma. Lancet 2017, 390, 2183-2193. [CrossRef]

3. Quigley, H.A. Number of people with glaucoma worldwide. Br. J. Ophthalmol. 1996, 80, 389-393. [CrossRef] [PubMed]

4. Quigley, H.A.; Broman, A.T. The number of people with glaucoma worldwide in 2010 and 2020. Br. J. Ophthalmol. 2006, 90, 262-267. [CrossRef] [PubMed]

5. Susanna, R., Jr.; De Moraes, C.G.; Cioffi, G.A.; Ritch, R. Why Do People (Still) Go Blind from Glaucoma? Transl. Vis. Sci. Technol. 2015, 4, 1. [CrossRef] [PubMed]

6. Anderson, D.R. Normal-tension glaucoma (low-tension glaucoma). Indian J. Ophthalmol. 2011, 59 (Suppl. S1), 97-101. [CrossRef] [PubMed]

7. Choplin, N.T. Correlation of asymmetric damage with asymmetric intraocular pressure in normal-tension glaucoma (low-tension glaucoma). Arch. Ophthalmol. 1989, 107, 167-168. [CrossRef] [PubMed]

8. Abe, R.Y.; Gracitelli, C.P.; Diniz-Filho, A.; Tatham, A.J.; Medeiros, F.A. Lamina Cribrosa in Glaucoma: Diagnosis and Monitoring. Curr. Ophthalmol. Rep. 2015, 3, 74-84. [CrossRef] [PubMed]

9. Liu, B.; McNally, S.; Kilpatrick, J.I.; Jarvis, S.P.; O’Brien, C.J. Ageing and Ocular Tissue Stiffness in Glaucoma. Surv. Ophthalmol. 2017, in press.

10. Hall, J.K.; Andrews, A.P.; Walker, R.; Piltz-Seymour, J.R. Association of retinal vessel caliber and visual field defects in glaucoma. Am. J. Ophthalmol. 2001, 132, 855-859. [CrossRef]

11. Izzotti, A.; Bagnis, A.; Sacca, S.C. The role of oxidative stress in glaucoma. Mutat. Res. 2006, 612, $105-114$. [CrossRef] [PubMed]

12. Yildirim, O.; Ates, N.A.; Ercan, B.; Muslu, N.; Unlu, A.; Tamer, L.; Atik, U.; Kanık, A. Role of oxidative stress enzymes in open-angle glaucoma. Eye 2005, 19, 580-583. [CrossRef] [PubMed]

13. Dreyer, E.B.; Zurakowski, D.; Schumer, R.A.; Podos, S.M.; Lipton, S.A. Elevated glutamate levels in the vitreous body of humans and monkeys with glaucoma. Arch. Ophthalmol. 1996, 114, 299-305. [CrossRef] [PubMed]

14. Cavet, M.E.; Vittitow, J.L.; Impagnatiello, F.; Ongini, E.; Bastia, E. Nitric oxide (NO): An emerging target for the treatment of glaucoma. Investig. Ophthalmol. Vis. Sci. 2014, 55, 5005-5015. [CrossRef] [PubMed]

15. Anders, F.; Teister, J.; Liu, A.; Funke, S.; Grus, F.H.; Thanos, S.; von Pein, H.D.; Pfeiffer, N.; Prokosch, V. Intravitreal injection of $\beta$-crystallin $\mathrm{B} 2$ improves retinal ganglion cell survival in an experimental animal model of glaucoma. PLoS ONE 2017, 12, e0175451. [CrossRef] [PubMed]

16. Piri, N.; Song, M.; Kwong, J.M.; Caprioli, J. Modulation of $\alpha$ and $\beta$ crystallin expression in rat retinas with ocular hypertension-induced ganglion cell degeneration. Brain Res. 2007, 1141, 1-9. [CrossRef] [PubMed]

17. Liu, Y.; Zhou, Q.; Tang, M.; Fu, N.; Shao, W.; Zhang, S.; Yin, Y.; Zeng, R.; Wang, X.; Hu, G.; et al. Upregulation of $\alpha \mathrm{B}$-crystallin expression in the substantia nigra of patients with Parkinson's disease. Neurobiol. Aging 2015, 36, 1686-1691. [CrossRef] [PubMed]

18. Narayanan, S.; Kamps, B.; Boelens, W.C.; Reif, B. $\alpha$ B-crystallin competes with Alzheimer's disease $\beta$-amyloid peptide for peptide-peptide interactions and induces oxidation of Abeta-Met35. FEBS Lett. 2006, 580, 5941-5946. [CrossRef] [PubMed]

19. Heise, E.A.; Fort, P.E. Impact of diabetes on $\alpha$-crystallins and other heat shock proteins in the eye. J. Ocul. Biol. Dis. Infor. 2011, 4, 62-69. [CrossRef] [PubMed]

20. Kannan, R.; Sreekumar, P.G.; Hinton, D.R. $\alpha$ Crystallins in the retinal pigment epithelium and implications for the pathogenesis and treatment of age-related macular degeneration. Biochim. Biophys. Acta 2016, 1860, 258-268. [CrossRef] [PubMed]

21. Derham, B.K.; Harding, J.J. $\alpha$-Crystallin as a molecular chaperone. Prog. Retin. Eye Res. 1999, 18, 463-509. [CrossRef]

22. Garcia-Valenzuela, E.; Shareef, S.; Walsh, J.; Sharma, S.C. Programmed cell death of retinal ganglion cells during experimental glaucoma. Exp. Eye Res. 1995, 61, 33-44. [CrossRef] 
23. Wilsey, L.; Gowrisankaran, S.; Cull, G.; Hardin, C.; Burgoyne, C.F.; Fortune, B. Comparing three different modes of electroretinography in experimental glaucoma: Diagnostic performance and correlation to structure. Doc. Ophthalmol. Adv. Ophthalmol. 2017, 134, 111-128. [CrossRef] [PubMed]

24. Bayer, A.U.; Neuhardt, T.; May, A.C.; Martus, P.; Maag, K.P.; Brodie, S.; Lütjen-Drecoll, E.; Podos, S.M.; Mittag, T. Retinal morphology and ERG response in the DBA/2NNia mouse model of angle-closure glaucoma. Investig. Ophthalmol. Vis. Sci. 2001, 42, 1258-1265.

25. Bayer, A.U.; Danias, J.; Brodie, S.; Maag, K.P.; Chen, B.; Shen, F.; Podos, S.M.; Mittag, T.W. Electroretinographic abnormalities in a rat glaucoma model with chronic elevated intraocular pressure. Exp. Eye Res. 2001, 72, 667-677. [CrossRef] [PubMed]

26. Nork, T.M.; Ver Hoeve, J.N.; Poulsen, G.L.; Nickells, R.W.; Davis, M.D.; Weber, A.J.; Sarks, S.H.; Lemley, H.L.; Millecchia, L.L. Swelling and loss of photoreceptors in chronic human and experimental glaucomas. Arch. Ophthalmol. 2000, 118, 235-245. [CrossRef] [PubMed]

27. Hernandez, M.; Rodriguez, F.D.; Sharma, S.C.; Vecino, E. Immunohistochemical changes in rat retinas at various time periods of elevated intraocular pressure. Mol. Vis. 2009, 15, 2696-2709. [PubMed]

28. Liu, J.P.; Schlosser, R.; Ma, W.Y.; Dong, Z.; Feng, H.; Lui, L.; Huang, X.Q.; Li, D.W. Human $\alpha$ A- and $\alpha \mathrm{B}$-crystallins prevent UVA-induced apoptosis through regulation of $\mathrm{PKC} \alpha, \mathrm{RAF} / \mathrm{MEK} / \mathrm{ERK}$ and AKT signaling pathways. Exp. Eye Res. 2004, 79, 393-403. [CrossRef] [PubMed]

29. Losiewicz, M.K.; Fort, P.E. Diabetes impairs the neuroprotective properties of retinal $\alpha$-crystallins. Investig. Ophthalmol. Vis. Sci. 2011, 52, 5034-5042. [CrossRef] [PubMed]

30. Masilamoni, J.G.; Vignesh, S.; Kirubagaran, R.; Jesudason, E.P.; Jayakumar, R. The neuroprotective efficacy of $\alpha$-crystallin against acute inflammation in mice. Brain Res. Bull. 2005, 67, 235-241. [CrossRef] [PubMed]

31. Ousman, S.S.; Tomooka, B.H.; van Noort, J.M.; Wawrousek, E.F.; O'Connor, K.C.; Hafler, D.A.; Sobel, R.A.; Robinson, W.H.; Steinman, L. Protective and therapeutic role for $\alpha \mathrm{B}$-crystallin in autoimmune demyelination. Nature 2007, 448, 474-479. [CrossRef] [PubMed]

32. Doss, E.W.; Ward, K.A.; Koretz, J.F. Investigation of the 'fines' hypothesis of primary open-angle glaucoma: The possible role of $\alpha$-crystallin. Ophthalmic Res. 1998, 30, 142-156. [CrossRef] [PubMed]

33. Chiu, K.; Zhou, Y.; Yeung, S.C.; Lok, C.K.; Chan, O.O.; Chang, R.C.; So, K.F.; Chiu, J.F. Up-regulation of crystallins is involved in the neuroprotective effect of wolfberry on survival of retinal ganglion cells in rat ocular hypertension model. J. Cell. Biochem. 2010, 110, 311-320. [CrossRef] [PubMed]

34. Thanos, S.; Bohm, M.R.; Zu Hörste, M.M.; Prokosch-Willing, V.; Hennig, M.; Bauer, D.; Heiligenhaus, A. Role of crystallins in ocular neuroprotection and axonal regeneration. Prog. Retin. Eye Res. 2014, 42, 145-161. [CrossRef] [PubMed]

35. Bohm, M.R.; Prokosch, V.; Bruckner, M.; Pfrommer, S.; Melkonyan, H.; Thanos, S. $\beta$ B2-Crystallin Promotes Axonal Regeneration in the Injured Optic Nerve in Adult Rats. Cell Transplant. 2015, 24, 1829-1844. [CrossRef] [PubMed]

36. Bohm, M.R.; Pfrommer, S.; Chiwitt, C.; Bruckner, M.; Melkonyan, H.; Thanos, S. Crystallin- $\beta$-b2-overexpressing NPCs support the survival of injured retinal ganglion cells and photoreceptors in rats. Investig. Ophthalmol. Vis. Sci. 2012, 53, 8265-8279. [CrossRef] [PubMed]

37. Fischer, D.; Hauk, T.G.; Muller, A.; Thanos, S. Crystallins of the $\beta / \gamma$-superfamily mimic the effects of lens injury and promote axon regeneration. Mol. Cell. Neurosci. 2008, 37, 471-479. [CrossRef] [PubMed]

38. Muller, A.; Hauk, T.G.; Leibinger, M.; Marienfeld, R.; Fischer, D. Exogenous CNTF stimulates axon regeneration of retinal ganglion cells partially via endogenous CNTF. Mol. Cell. Neurosci. 2009, 41, 233-246. [CrossRef] [PubMed]

39. Pucci, S.; Mazzarelli, P.; Missiroli, F.; Regine, F.; Ricci, F. Neuroprotection: VEGF, IL-6, and clusterin: The dark side of the moon. Prog. Brain Res. 2008, 173, 555-573. [PubMed]

40. Samejima, K.; Svingen, P.A.; Basi, G.S.; Kottke, T.; Mesner, P.W., Jr.; Stewart, L.; Durrieu, F.; Poirier, G.G.; Alnemri, E.S.; Champoux, J.J.; et al. Caspase-mediated cleavage of DNA topoisomerase I at unconventional sites during apoptosis. J. Biol. Chem. 1999, 274, 4335-4340. [CrossRef] [PubMed]

41. Okinaga, T.; Kasai, H.; Tsujisawa, T.; Nishihara, T. Role of caspases in cleavage of lamin A/C and PARP during apoptosis in macrophages infected with a periodontopathic bacterium. J. Med. Microbiol. 2007, 56, 1399-1404. [CrossRef] [PubMed] 
42. Anders, F.; Teister, J.; Funke, S.; Pfeiffer, N.; Grus, F.; Solon, T.; Prokosch, V. Proteomic profiling reveals crucial retinal protein alterations in the early phase of an experimental glaucoma model. Graefe's Arch. Clin. Exp. Ophthalmol. 2017, 255, 1395-1407. [CrossRef] [PubMed]

43. Burke, B. Lamins and apoptosis: A two-way street? J. Cell Biol. 2001, 153, F5-F7. [CrossRef] [PubMed]

44. Broers, J.L.; Bronnenberg, N.M.; Kuijpers, H.J.; Schutte, B.; Hutchison, C.J.; Ramaekers, F.C. Partial cleavage of A-type lamins concurs with their total disintegration from the nuclear lamina during apoptosis. Eur. J. Cell Biol. 2002, 81, 677-691. [CrossRef] [PubMed]

45. Cross, T.; Griffiths, G.; Deacon, E.; Sallis, R.; Gough, M.; Watters, D.; Lord, J.M. PKC-delta is an apoptotic lamin kinase. Oncogene 2000, 19, 2331-2337. [CrossRef] [PubMed]

46. Adhikari, A.S.; Sridhar Rao, K.; Rangaraj, N.; Parnaik, V.K.; Mohan Rao, C. Heat stress-induced localization of small heat shock proteins in mouse myoblasts: Intranuclear lamin A/C speckles as target for $\alpha \mathrm{B}$-crystallin and Hsp25. Exp. Cell Res. 2004, 299, 393-403. [CrossRef] [PubMed]

47. Ivanov, D.; Dvoriantchikova, G.; Nathanson, L.; McKinnon, S.J.; Shestopalov, V.I. Microarray analysis of gene expression in adult retinal ganglion cells. FEBS Lett. 2006, 580, 331-335. [CrossRef] [PubMed]

48. Springelkamp, H.; Iglesias, A.I.; Cuellar-Partida, G.; Amin, N.; Burdon, K.P.; van Leeuwen, E.M.; Gharahkhani, P.; Mishra, A.; van der Lee, S.J.; Hewitt, A.W.; et al. ARHGEF12 influences the risk of glaucoma by increasing intraocular pressure. Hum. Mol. Genet. 2015, 24, 2689-2699. [CrossRef] [PubMed]

49. Chowdhury, U.R.; Madden, B.J.; Charlesworth, M.C.; Fautsch, M.P. Proteome analysis of human aqueous humor. Investig. Ophthalmol. Vis. Sci. 2010, 51, 4921-4931. [CrossRef] [PubMed]

50. Bonnemann, C.G.; Thompson, T.G.; van der Ven, P.F.; Goebel, H.H.; Warlo, I.; Vollmers, B.; Reimann, J.; Herms, J.; Gautel, M.; Takada, F.; et al. Filamin C accumulation is a strong but nonspecific immunohistochemical marker of core formation in muscle. J. Neurol. Sci. 2003, 206, 71-78. [CrossRef]

51. Hagemann, T.L.; Boelens, W.C.; Wawrousek, E.F.; Messing, A. Suppression of GFAP toxicity by $\alpha \mathrm{B}$-crystallin in mouse models of Alexander disease. Hum. Mol. Genet. 2009, 18, 1190-1199. [CrossRef] [PubMed]

52. Prokai-Tatrai, K.; Xin, H.; Nguyen, V.; Szarka, S.; Blazics, B.; Prokai, L.; Koulen, P. 17 $\beta$-estradiol eye drops protect the retinal ganglion cell layer and preserve visual function in an in vivo model of glaucoma. Mol. Pharm. 2013, 10, 3253-3261. [CrossRef] [PubMed]

53. Funke, S.; Perumal, N.; Beck, S.; Gabel-Scheurich, S.; Schmelter, C.; Teister, J.; Gerbig, C.; Gramlich, O.W.; Pfeiffer, N.; Grus, F.H. Glaucoma related Proteomic Alterations in Human Retina Samples. Sci. Rep. 2016, 6, 29759. [CrossRef] [PubMed]

54. Shareef, S.R.; Garcia-Valenzuela, E.; Salierno, A.; Walsh, J.; Sharma, S.C. Chronic ocular hypertension following episcleral venous occlusion in rats. Exp. Eye Res. 1995, 61, 379-382. [CrossRef]

55. Nadal-Nicolas, F.M.; Jimenez-Lopez, M.; Sobrado-Calvo, P.; Nieto-Lopez, L.; Canovas-Martinez, I.; Salinas-Navarro, M.; Vidal-Sanz, M.; Agudo, M. Brn3a as a marker of retinal ganglion cells: Qualitative and quantitative time course studies in naive and optic nerve-injured retinas. Investig. Ophthalmol. Vis. Sci. 2009, 50, 3860-3868. [CrossRef] [PubMed]

56. Rappsilber, J.; Mann, M.; Ishihama, Y. Protocol for micro-purification, enrichment, pre-fractionation and storage of peptides for proteomics using StageTips. Nat. Protoc. 2007, 2, 1896-1906. [CrossRef] [PubMed]

57. Bluhm, A.; Casas-Vila, N.; Scheibe, M.; Butter, F. Reader interactome of epigenetic histone marks in birds. Proteomics 2016, 16, 427-436. [CrossRef] [PubMed]

58. Vizcaino, J.A.; Csordas, A.; Del-Toro, N.; Dianes, J.A.; Griss, J.; Lavidas, I.; Mayer, G.; Perez-Riverol, Y.; Reisinger, F.; Ternent, T.; et al. 2016 update of the PRIDE database and its related tools. Nucleic Acids Res. 2016, 44, D447-D456. [CrossRef] [PubMed]

(C) 2017 by the authors. Licensee MDPI, Basel, Switzerland. This article is an open access article distributed under the terms and conditions of the Creative Commons Attribution (CC BY) license (http:/ / creativecommons.org/licenses/by/4.0/). 